\title{
Livelihood Impact and Risk Management of Drought: The Experiences of Farming Households in the Free State Province, South Africa
}

Gideon Danso-Abbeam ( $\nabla$ dansoabbeam@uds.edu.gh )

University for Development Studies https://orcid.org/0000-0002-7971-4676

Abiodun 0 Ogundeji

University of the Free State - Bloemfontein Campus: University of the Free State

Temitpoe 0 Ojo

Obafemi Awolowo University

Collins C. Okolie

University of the Free State - Bloemfontein Campus: University of the Free State

\section{Research Article}

Keywords: Drought-risk management, Seemingly unrelated regression, Perceived impact, Thaba Nchu

Posted Date: May 24th, 2021

DOI: https://doi.org/10.21203/rs.3.rs-429190/v1

License: (c) (i) This work is licensed under a Creative Commons Attribution 4.0 International License.

Read Full License 
1 Livelihood Impact and Risk Management of Drought: The Experiences of Farming 2 Households in the Free State Province, South Africa

3

$4 \quad{ }^{1,2}$ Gideon Danso-Abbeam*, ${ }^{2}$ Abiodun A. Ogundeji, ${ }^{3,4}$ Temitope O. Ojo, ${ }^{2}$ Collins C. Okolie

$5{ }^{1}$ Department of Agricultural and Resource Economics, University for Development Studies, 6 Tamale, Ghana.

$7{ }^{2}$ Department of Agricultural Economics, University of the Free State, Bloemfontein, South 8 Africa

$9 \quad{ }^{3}$ Department of Agricultural Economics, Obafemi Awolowo University, IIe-Ife, Nigeria

10

11

12

13

14

15

16

17

18

19

20

21

22

23

24

25

${ }^{4}$ Disaster Management Training and Education Centre for Africa, University of the Free State, South Africa$$
\text { . }
$$

\section{*Corresponding author's email address: dansoabbeam@uds.edu.gh}


Abstract

27

Drought is one of the main causes of food insecurity, malnutrition and poverty. It is therefore important to understand the perception of farmers on socioeconomic and environmental impacts of drought and the strategies employed to manage it. Using data collected from 301 smallholder households in Thaba Nchu, Free State Province, the study contributes to three perspectives: analysing the perceived socio-economic and environmental impact of drought, examining the determinants of the perceived impact, and identifying factors affecting the intensity of drought-risk management practices used by smallholder farming households. Using 11 indicators as a measure of perceived impact, the findings from the principal component analysis (PCA) revealed three main dimensions of perceived drought impact: economic, environmental and social impacts. Different socio-economic and institutional factors have a different influence on the three dimensions. In addition, factors such as age, household size, non-farm work and extension services are significant in determining the intensity of drought-risk management strategies implemented by farmers in the study area. The study therefore recommends that climate risk management be integrated into the provision of extension services, particularly in drought-prone areas such as the Free State Province. Encouraging farmers to engage in non-agricultural economic activities is also crucial, as this can serve as insurance against events such as drought. Thaba Nchu. 


\section{Introduction}

The evidence of climate change is real, and its impacts is felt all over the world, with agricultural households in both developed and developing economies suffering the most (Wang, 2021). Agricultural production in sub-Saharan Africa (SSA) is highly dependent on weather patterns, particularly high temperatures and rainfall. With the rise in global temperature, inter-annual temperature and precipitation variability will also increase (Dai, 2013). For those whose livelihoods depends on agricultural activities, these irregular patterns of climate change pose serious difficulties (Linke et al., 2020). Intergovernmental Panel on Climate Change (IPCC 2014) indicated that "more frequent and/or longer heat waves and warms spells in Africa should be expected." Agriculture, the core use of land, is highly sensitive to extreme climate variations, and farmers are usually affected by the whims of climate change and variability (Shiferaw et al., 2014). Widely disparate weather and extreme climate variability poses the major challenge to smallholder farmers and limits their overall human development. (Hellmuth et al., 2009; Shiferaw et al., 2014). Rainfall is one of the climatic factors whose variability has a major impact on farmers' livelihoods, particularly the poor and marginalized, as a result of its impact on plants and livestock (Nanganga and Safalaoh, 2020).

Extreme variability in rainfall patterns leads to floods and droughts, leading to a reduction in GDP growth in many SSA countries (Kogo et al., 2020). Drought is considered to be the most devastating climate-related events in the world, causing serious damage to agricultural, environmental and socioeconomic activities (Moeletsi and Walker, 2012). Drought occurs when there is a lack of sufficient rainfall over a long period of time (usually months) leading to water shortages and adverse impacts on the lives of people, animals and the loss of vegetation (Msangi, 2004). Apart from a decrease in rainfall giving rise to drought, drought can also result from human activities such as a change in land use (Keesstra, 2007; Mohmmed et al., 2018). 
Essentially, the occurrence of drought can be divided into four main factors, depending on the impact: agricultural, socioeconomics, meteorological and hydrological (Thilakarathne and Sridhar, 2017). The frequency and severity of droughts have increased significantly in recent years as a result of climate change and agricultural activities in developing economies such as Africa countries (Panthi et al., 2016).

South Africa has relatively less rainfall; therefore it is generally described as a semi-arid and water-stressed country (Botai et al., 2016). The average annual rainfall in the country is around $450 \mathrm{~mm}$, which is well below the global average of about $860 \mathrm{~mm}$ per year. The country experiences seasonal rainfall variations, with most rainfall occurring during summer periods (usually November - March). However, most of the areas in eastern Highveld receive between $500 \mathrm{~mm}$ and $900 \mathrm{~mm}$ amount of rainfall per year while provinces such as Free State and Northwest receive less than 500mm of rainfall per year. This insufficient rainfall usually leads to drought, especially in those areas with less rainfall. Drought events in South Africa are common, occurring at different intensities in different parts of the country, and 2015 remains the driest year in the last 10 decades (South African Weather Services [SAWS], 2015). As a result, the rural smallholder farmers are most affected and the production systems are threatened by extreme weather conditions which cause thermal stress in plants and livestock (Maponya and Mpandeli, 2013). For example, drought is the main climate-related hazard in the Free State Province of South Africa, with the most devastating impact on farmers' crops and livestock (Botai et al., 2016). Botai et al. (2016) noted that frequency and severity of drought was more pronounced in Free State Province than in other parts of South Africa.

Smallholder farmers who are most affected by extreme weather conditions such as drought have long history of risk management techniques to mitigate the effects of the events. Drought Risk Management (DRM) can be defined as strategies put in place to mitigate adverse effects while trying to pursue positive objectives (Hansen et al. 2004). DRM is part of climate risk 
management techniques that refer to climate mitigation strategies decision-making, where farmers use the information they receive to take action to minimize climate risk and exploit climate opportunities (Hellmuth et al., 2009; Shiferaw et al., 2014). DRM tools can be divided into two: ex-ante DRM (coping mechanisms) and ex-post (adaptation mechanisms), depending on whether the strategy reduce risk exposure or minimize the impact of undesirable outcomes after the shock (Owens et al., 2003). More often than not, farmers dwelling in drought-prone areas modify their production systems such that the likely impacts of the shock could be minimized within acceptable level.

Ex-ante strategies are considered as consumption-smoothen tools as they help to reduce income fluctuations. There are two main ways of ex-ante coping strategies: diversification and application of flexible decision-making. Diversification involves a shift from mono-cropping to the planting of a broader plants /and rearing of livestock, and engagement in other non-farm activities to help combat risk of extreme conditions (Shiferaw et al., 2014). These include temporary adjusting the use farm resources based on climatic conditions and adjusting plant population. Farmers in SSA used other DRM strategies such as maintaining flexible decisionmaking (e.g., planting of drought-tolerant crops), irrigation/water harvesting, and insurance expenditure below certain threshold as a result of climatic shocks. Depending on how serious the shock may be, farming households employ varied range of ex-post DRM strategies such as liquidation of farm assets (e.g., land, livestock, etc.), and reduction of consumption, particularly on non-essential items (e.g., clothing, social functions, etc.). Households, sometimes also rely on insurance schemes, public relief and safety net programs (interevention from government 
and NGOs). Smallholder farmers can not handle or cope with the situation during drought periods without external assistance from governmental and non-governmental agencies (South African Government Gazette 2005). Dryness can result in food scarcity and social unrest, and land distribution can become stagnant. Drought has forced farmers in many areas to sell some of their livestock in order to buy fodder for the rest (Mudombi 2011). Hence, the importance of insurance, safety-nets and government relief packages. Irrespective of the measures put in place by farmers or an agency to mitigate the effects of the shocks, how farmers perceived the impact of drought is key to facilitate the support of policy-related DRM strategies.

Perception and DRM strategies are the two significant elements in the process of adaptation. Farmers first need to perceived the impact of drought in order to help them take appropriate action to mitigate their vulnerability and build their adaptive capacity (Bryan et al., 2009). Misleading perceptions about the consequences of climate change and variability may lead to no action taken to manage the risk. However, farmers who perceive potential consequences of extreme weather conditions such as drought are more likely to take precautionary measures to minimize its effects and support programs that aims to address it (Niles et al., 2013). Drought impacts on smallholder farmers result from the interaction between natural events and the demand farmers place on the water supply. There are three impacts of droughts: economic, social and environmental. Economic impacts of drought have to do with the effects of drought on food security, malnutrition, food prices and reduction of household income. For example, in South Africa, many farming households experienced persistent food insecurity, malnutrition and reduction in income levels during extended period of drought. Thus, drought is an important factor in increasing food insecurity, and is strongly linked to periods of vulnerability as a result of climate stress. Food prices, particularly staples are usually high during the period of drought, which results in hunger and malnutrition, as the low-income group cannot afford the high prices of food. The social impact of drought refers to impact such as public safety, 
conflicts between water users, and reduced quality of life. One of the significant social impact is population migration. Those that migrate usually migrate to urban areas, or areas outside the drought regions. The migrants hardly ever return home, even when the drought is less intense, which results in the deprivation of valuable human resources in rural areas. The environmental impact of drought results in damage to air and water quality, plant and animal species, forest and range fires and wildlife habitats, degradation of landscape quality and loss of biodiversity. Some of the effects are short term, and conditions return to normal after or at the end of the drought period. Other environmental effects last for a long period of time, which may even result in them becoming permanent. The degradation of landscape quality may possibly lead to a more permanent loss of biological productivity (Wilhite and Vanyarkho 2000). Baiyegunhi, 2020; Thinda et al., 2020) have analysed factors influencing farmers' perception of climate change in general and their adaptation strategies. However, studies on how farmers perceived the impact of drought and factors influencing the perceived impact of drought is very analysis was used to generate three key perceived impact: economic, environmental and social with 11 questions based on five-point Likert scale. Second, the study extends beyond considering how farmers perceived the consequences of drought to identify the determinants of perceived impact of drought through the application of seemingly unrelated regression (SUR) where economic, environmental and social dimensions of the perceived impact were used as the dependent variables. Finally, the study examines factors that influence the number of DRM strategies employed (intensity) to mitigate the risk and the negative outcomes of 177 drought. In this case, the intensity of DRM was treated as dependent variable and fitted into 
178 Count data model, precisely Poisson and negative binomial regression models. As the 179 frequency of drought increases across the globe, particularly in the Free State province of South 180 Africa, understanding how farmers perceived the negative consequences of drought and the 181 factors influencing these perceptions, as well as the measures taken to mitigate the risk and the 182 outcomes may be critical to design and implement technological and institutional policy options.

\section{Methodology}

\subsection{Analytical frameworks}

This study followed economic theory in order to achieve its objectives. First, PCA was used to generate indices of farmers' perception of the impact of drought on their livelihoods on the basis of a series of questions. Second, a seemingly unrelated regression (SUR) analysis was used to identify factors that affect farmers' perceptions of the impact of drought. Finally, count data modelling was used to examine the determinants of the intensity of the DRM strategies (intensity is defined as the number of drought-risk management) adopted by farmers to deal with the outcome of the drought. The following sections discuss the analytical techniques referred to above.

\subsubsection{Principal component analysis}

Multivariate analysis, particularly PCA, is one of the most commonly used approaches to identify the best possible combinations of a number of factors or variables that are thought to influence the outcome. The PCA technique reduces the dimensionality of the data sets while minimizing the loss of information. In this study, PCA was used to reduce the dimensionality of measuring the perceived impact of drought on farmers. The PCA creates uncorrelated 
202

203

204

205

206

207

208

209

210

211

212

213

214

215

indices where each index is a linear weighted combination of the initial element of the perceived impact (Thomas et al., 2011). The elements are ordered in the order of the first part (PC1) which describes all variables in the original data as the greatest possible variation (Filmer \& Pritchett, 2001). Following Wale et al. (2021), PCA for this study was expressed as follows. Consider that the following matrix denote the relationship between farmers' perceived impact of drought and a set of explanatory variables:

$$
\left[\begin{array}{c}
D_{1} \\
\cdot \\
\cdot \\
D_{n}
\end{array}\right]=\left[\begin{array}{c}
\beta_{01} \\
\cdot \\
\cdot \\
\beta_{0 n}
\end{array}\right]+\left[\begin{array}{c}
\beta_{1 j} \\
\cdot \\
\cdot \\
\beta_{n j}
\end{array}\right] x_{j}+\left[\begin{array}{c}
\varepsilon_{1} \\
\cdot \\
\cdot \\
\varepsilon_{n}
\end{array}\right]
$$

where $D_{1} \ldots . D_{n}$ are set of $n$ dependent variables measuring perceived impact of drought, which can be expressed as a function of a set of independent variables $\left(x_{i}\right)$ with parameter estimates $\left(\beta_{1 j} \ldots . . \beta_{n j}\right)$, intercepts $\left(\beta_{01} \ldots \ldots \beta_{0 n}\right)$ and error terms $\left(\varepsilon_{1} \ldots \varepsilon_{n}\right)$. The coefficient of the above equation could be estimated through linear structural equations based on the assumption that the dependent variable $D_{1} \ldots D_{n}$ has a latent variables of the original observable dependent variables. We can apply PCA to the left-side of equation (1) to get equation (2) as follows:

$$
\left[\begin{array}{c}
D_{1} \\
\cdot \\
\cdot \\
D_{n}
\end{array}\right] \cong\left[\begin{array}{c}
P_{1} \\
\cdot \\
\cdot \\
P_{k}
\end{array}\right]=\left[\begin{array}{c}
\beta_{01} \\
\cdot \\
\cdot \\
\beta_{0 k}
\end{array}\right]+\left[\begin{array}{c}
\beta_{1 j} \\
\cdot \\
\cdot \\
\beta_{k j}
\end{array}\right] x_{j}+\left[\begin{array}{c}
\varepsilon_{1} \\
\cdot \\
\cdot \\
\varepsilon_{k}
\end{array}\right],
$$

where $P_{1} \ldots P_{k}$ denote principal components that have eigenvalues greater than one and $k<n$. $k$ can be equal to one, where only one factor is retained or greater than one where more than one factors are retained as in the case of this study (see Table 3).

\subsubsection{Seemingly Unrelated Regression analysis}


221 Seemingly unrelated regression analysis was applied to the three dimensions (D1, D2 and D3)

222 or components obtained from the PCA analysis. This is to acknowledge that the principal

223 motive here is about how farmers perceived impact of drought on their livelihoods. The SUR

224 enables us to identified the determinant of perceived impact of droughts from the three key

225 perspectives: economic, environmental and social. SUR is a system of equations that are correlated across equations for an individual but uncorrelated across equations. Estimating the three equations (D1, D2 and D3) through SUR produces consistent and efficient parameter estimates as opposed to estimating each equation separately using ordinary least square technique. This is because SUR ignores the possibility of the residuals of the equations been correlated(Cameron and Trivedi, 2010).

The perceived impact of drought equations with three dependent variables can be estimated through SUR as follows:

$d_{1}=\alpha_{1} X_{1}+\varepsilon_{1}$

$d_{2}=\alpha_{2} X_{2}+\varepsilon_{2}$,

$$
d m=\alpha_{m} X_{m}+\varepsilon_{m}
$$

234 These equations are described as seemingly unrelated regression model and can expressed as;

$d_{i}=\alpha_{i} X_{i}+\varepsilon_{i}, \quad i=1, \ldots \ldots d$

The SUR model is based on the assumption that the residuals have zero mean or the $X_{i}$ are strictly exogenous, homoscedastic and uncorrelated across observations. However, the equations within the system is correlated. 
243

244

263
The number of strategies used by individual farmers described the dependent variable in order to identify factors that influence the intensity of the drought-risk management strategies. Cameron and Trivedi (1990) argued that the number of strategies adopted was a measure of intensity or diversity. Following Cameron and Trivedi (1990) and discussed in a number of studies such as Nkegbe and Shankar (2014), Mahama et al. (2020), Israel et al. (2020), the number of drought-risk management strategies used by farmers could be modelled by count data modelling. This is because the number of drought-risk management strategies used is counted in its natural form. The count data are non-normal and therefore cannot be estimated by the ordinary least square (OLS) estimator (Maddala and Flores-Lagunes, 2001). Standard regression models commonly used for count data analysis are Poisson regression and Negative binomial. The Poisson regression has the basic assumption of equidispersion (equality of variance and mean) while the negative binomial is responsible for over-dispersion (variance greater than mean). In a situation where the variance is less than the mean (under-dispersion) the Generalized Poisson regression analysis may be used. Zero-inflated Poisson and zeroinflated negative binomial are other types of count data models used to account for frequent zeros in the data (i.e. where zeros are more than expected.

Preliminary analysis of the sample data indicates that there are no excess zeros and that there is equidispersion. Thus, the Poisson regression model is well suited to the data set and is therefore used for analysis. Following Greene (2008), Poisson regression has a density function expressed as;

$$
\operatorname{Pr}(H=h)=\frac{\lambda^{-\delta(h)} \delta_{i}(h)^{H}}{\Phi(1+H)}
$$


264 Where; $\delta_{i}=\operatorname{Exp}\left(\Omega+L^{\prime} \psi\right)$ and $H_{i}=0,1, \ldots i$ is the number of drought-risk management 265 practices employed, and $L$ is a set of predictors. $\Omega$ and $\psi$ are the parameter estimates. Greene 266 (2008) observed that the number of drought-risk management strategies used, $\delta$ is given as:

\subsection{The study area, sampling and data collection techniques}

269

270

271

272

The survey was conducted in Thaba Nchu, Mangaung District of the Free State Province of South Africa. The district of Mangaung is centrally located in the province of Free State and covers a total land area of approximately $9887 \mathrm{~km} 2$ and a population of approximately 747,431 people (Statistics South Africa [Stats SA] 2011). The district is considered to be one of the most diverse economies and the largest contributor to GDP in the province of Free State (Mangaung Metropolitan Municipality Draft Integrated Development Plan 2017). Thaba Nchu is located $67 \mathrm{~km}$ east of Bloemfontein and has a more scattered pattern of development, with 37 villages surrounding the city centre. Agriculture and its related activities are the main source of livelihood. Residents are mainly smallholder farmers who cultivate maize, sunflower, wheat, potatoes, soybean and sorghum. Livestock breeding, mainly cattle and poultry, is also a major agricultural activity in the Thaba Nchu area. Figure 1 shows the map of the Manguang district of Thaba Nchu. 


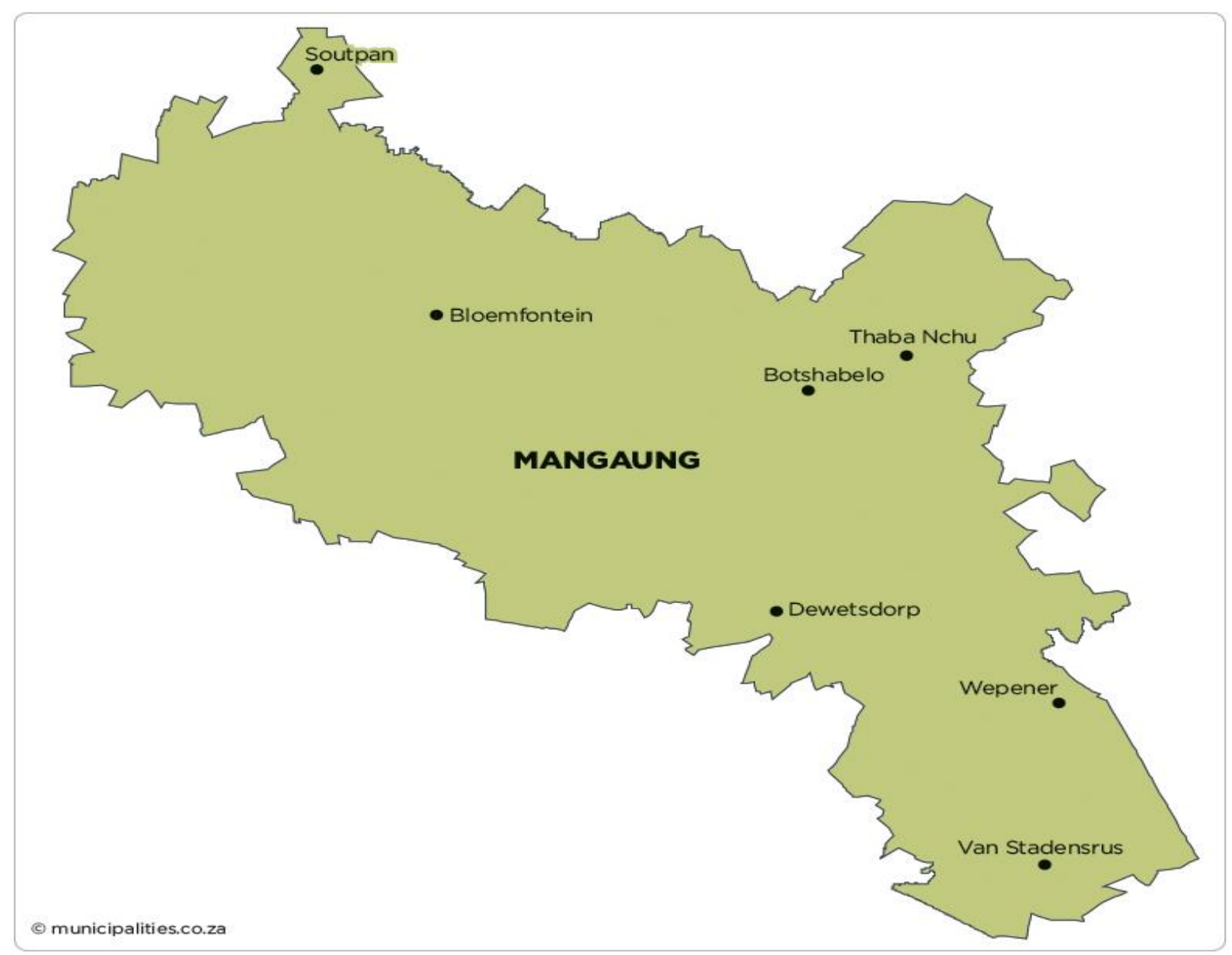

Figure 1: A map of Mangaung district showing Thaba Nchu Municipality, Free State Province, South Africa.

A multi-stage survey method was used and the Free State Province was predefined due to the prevalence of drought in recent years. The first stage of the survey was the random selection of Thaba Nchu from the many agricultural municipalities in the province of Free State. Thaba Nchu was then stratified into three strata: central, northern and southern, where appropriate sampling was applied to selected communities from each stratum. This is because there are 12 , 21 and 12 communities in central, southern and northern Thaba Nchu, respectively. As a result, we selected two communities each from Central and Northern Thaba Nchu, while four communities were selected from Southern Thaba Nchu. With a simple random sampling technique, 40 farming households from each community were selected, making a total of 320 targeted respondents. However, a response rate of $94 \%$ was achieved, bringing the total sample 
size used for this study to approximately 301 respondents. Data was collected through a faceto-face interview using a comprehensive and well-structured questionnaire.

\section{Results and discussions}

\subsection{Use of drought-risk management practices}

Over the years, agricultural households have engaged in a number of risk management practices to minimize the negative impact of extreme weather variability, such as drought and floods. The Drought Risk Management Strategies identified in the study area are shown in Table 1. The most important aspect may not be the management practices themselves, but the way they are used or the benefits they receive. This section examines the different risk management practices chosen by farmers in response to drought on the basis of their available resources and external assistance. Some of these management strategies are used by farmers to avoid higher incomes and consumption shortfalls, while others are designed by stakeholders to help farmers recover or manage the risk of the event. Table 2 shows that the drought management strategy most frequently used in the study area was NGO intervention, which was used by $50.30 \%$ of farmers, followed by rainwater harvesting and the use of reserves/residues by $27.72 \%$ and $25.68 \%$ of farmers, respectively. Some farmers also managed the situation by either mortgaging their farmland or selling assets such as livestock, clothing, etc. Moreover, $16.60 \%$ of farmers sought employment elsewhere to cope with the event of drought, and $25.25 \%$ of farmers depended on government intervention as a means of coping strategy. The dependency on the government support program to help farmers overcome drought shock confirms the report by Shoroma (2014), which found that farmers in the village of Setlagole depended on the government to assist them with the necessary relief mechanisms to reduce the impact of the drought. 


\begin{tabular}{lc}
\hline Drought-risk management strategies & Percentage of farmers applied \\
\hline NGO intervention in the community & \\
(safety net program) & 50.3 \\
Seek new sources of food & 5.11 \\
Seek for employment somewhere & 16.6 \\
Keep reserves/residues & 25.68 \\
Selling of assets (e.g., farmland and & \\
livestock) & 18.25 \\
Rainwater harvesting & 27.72 \\
Maintaining flexibility & 3.00 \\
Government assistance & 25.25 \\
Crop insurance compensation & 20.86 \\
\hline
\end{tabular}

Another drought-risk management tool that is considered to be very important, but with less attention, is crop insurance or weather insurance. As indicated in Table 1, some $21 \%$ of respondents benefited from insurance as a coping strategy during drought. The increasing frequency and severity of droughts require the promotion of crop insurance; as financial institutions may not lend to smallholder farmers if they suspect a higher risk of default due to drought. Crop insurance, such as weather-based insurance, may be an attractive approach to managing drought-risk, as it uses weather indices such as rainfall to determine farmers' payouts and is faster and less dubious. As a result, insurance against extreme weather conditions can be more attractive and convenient to manage the risk of drought, especially for low-income farmers in Sub-Saharan Africa. Smallholder farmers in Thaba Nchu do not maintain flexibility as $97 \%$ of respondents did not use any flexibility maintenance as a coping strategy. Maintaining flexibility is a management strategy that allows households to switch between activities such as adjustment of input use (e.g. drought-tolerant crop varieties) as needed. In addition, the second least-used coping strategy in Thaba Nchu was to seek new food sources $(5.0 \%)$. Although most farmers have used multiple management practices, some are beneficial, while others have perpetual adverse effects on their poverty situations. The incidence of drought is causing loss of assets to cope with the impact, widening the net trap of poverty and extreme poverty. Poor households that sell their assets may not be able to recover and have been trapped 
in the vicious cycle of poverty. Tesso et al. (2012) noted that poor households who sold their assets to cope with drought stress are about $18 \%$ less likely to recover. Some other strategies adopted to manage the negative impact of drought (e.g. migration to other areas of employment) could have a negative impact on family relationships as well as on knowledge capital.

\subsection{Summary of descriptive statistics of the independent variables in the model}

347 Descriptive statistics on the socio-economic variables used in the models to achieve the study objective are shown in Table 2. The proportion of males in the sample was 0.4 , indicating that the majority of female respondents were female $(60 \%)$. The average age was 53 years, with a relatively long farming experience of around 19 years. However, our respondents have a relatively low level of education, with an average of 9 years of formal education. Larger house sizes can be beneficial to households if they serve as a source of agricultural labour. However, more household members are exerting pressure on household food consumption, shelter and other resources. The results showed that the average household size was approximately 4.

Table 2: Description of independent variables

\begin{tabular}{|c|c|c|c|}
\hline Independent variables & Description & Mean & Std \\
\hline Proportion of male & 1 if male; 0 otherwise & 0.45 & 0.49 \\
\hline Age & Age of respondent in year & 53.4 & 15.33 \\
\hline Educational attainment & Number of years in formal education & 8.63 & 3.6 \\
\hline Experience & Number of years in farming & 19.18 & 13.68 \\
\hline Household size & Number of members in a household & 3.77 & 1.96 \\
\hline Non-farm work & $\begin{array}{l}1 \text { if respondent engages in non-farm job; } 0 \text { otherwise } \\
1 \text { if respondent undertakes seasonal farming; } 0\end{array}$ & 0.6 & 0.32 \\
\hline Seasonal farming & otherwise & 0.67 & 0.47 \\
\hline $\begin{array}{l}\text { Membership of farmer } \\
\text { associations }\end{array}$ & $\begin{array}{l}1 \text { if respondent is member of farmer associations; } 0 \\
\text { otherwise }\end{array}$ & 0.45 & 0.44 \\
\hline Access to extension services & Number of contacts with extension agents & 2.78 & 1.41 \\
\hline $\begin{array}{l}\text { Access to climate change } \\
\text { information }\end{array}$ & $\begin{array}{l}1 \text { if respondent access climate change information; } 0 \\
\text { otherwise }\end{array}$ & 0.38 & 0.31 \\
\hline Drought frequency & $\begin{array}{l}\text { Number of times households experience drought in } \\
\text { the last five years }\end{array}$ & 1.78 & 1.18 \\
\hline
\end{tabular}



irrigation, mixed-cropping, multi-cropping and livestock farming. Irrigation and mixing of livestock and crops is one of the best adaptation measures in dry soil conditions (Hassan and Nhemachena, 2008). Dissemination of information is key to managing any kind of risk, including drought. Sources of information, such as farmer groups and extension services, as well as access to climate change information (e.g. information on early warning systems) are therefore key to managing the risk of drought. Table 2 shows that some $45 \%$ are members of the farmer group, while $38 \%$ have access to climate change information. On average, respondents had twice access to extension services in the year under study and had less than once experience of drought in the last five years.

\subsection{Perceived impact of drought on livelihoods}

This section presents the descriptive statistics (mean and standard deviations) of the 11 questions answered by our respondents on the perceived impact of drought and the results of the PCA analysis of the impact of drought as perceived by the respondents.

\subsubsection{Descriptive statistics of the perceived impact of drought}

The impact of drought on human life and the environment as perceived by the respondents is shown in Table 3. The severity of the effects of each indicator was measured at a scale of 1-5, with 1 being not severe and 5 being very severe. On average, farmers perceived drought as causing severe reductions in farm incomes and threatening their food security status. Drought outcomes include outbreaks of disease and pests, lack of water for plants and livestock, resulting in reduced crop yields and livestock deaths. They did not find much trouble, however, in their inability to take food rather than malnutrition. With regard to wildlife migration and frequent wild fires, they believe that drought has an important role to play. The mean severity 

some serious consequences for their water bodies.

Table 3. Indicators of farmers' perceived impact of drought

\begin{tabular}{lcc}
\hline Impact indicators & Mean score & Standard deviation \\
\hline Reduction in farm income & 4.0697 & 1.0856 \\
Threatening food security & 3.5647 & 0.8286 \\
Unable to take preferred meal & 1.9867 & 1.0518 \\
Causes malnutrition & 2.4186 & 1.0789 \\
Migration of wildlife & 3.9402 & 1.305 \\
Loss of vegetation & 2.5947 & 1.3887 \\
Frequent wild fires & 4.2525 & 1.4362 \\
Drying up of water resources & 3.75415 & 1.3364 \\
Unemployment & 2.7707 & 1.5046 \\
Population migration & 3.2059 & 1.2695 \\
Reduction of expenditure on social & & \\
festivities & 3.1129 & 1.2195 \\
\hline
\end{tabular}

383

In addition, farmers feel that drought has a moderate impact on unemployment, population migration and reduced spending on social festivities such as wedding ceremonies, naming ceremonies, festivals and funerals.

\subsubsection{Dimensions of the perceived impact of drought on livelihoods}

The PCA of the perceived impact of drought on the livelihoods of agricultural households in the Free State Province of South Africa produces three key factors with a value of $>1$, which explains about $55 \%$ of the total variation in the data set out in Table 4. Although there is no rule of thumb in the selection of the percentage variation, it is more appropriate and acceptable to consider at least $50 \%$ of the variation that could be attributed to the solution in studies such as this where the cross-section data used is susceptible to random errors (Hair Jr et al., 2014). The sampling adequacy of 0.81 , as measured by the Kaiser-Meyer-Oklin (KMO) and Bartlet sphericity test, which is significant at $1 \%$, confirms the adequacy of the PCA data. Field (2009) and Wale et al. (2021) has shown that a high KMO level indicates a relatively compact correlation pattern between variables and demonstrate that the factor analysis is more 
appropriate for the analysis of the data. The Cronbach Alpha Multi-Item Index of 0.78 shows that the 11 indicators are a reliable measure of the perceived impact of drought on livelihoods. Tavakol and Dennick (2011) noted that the Cronbach Alpha of 0.78 is an indication of a high level of internal consistency. It is also worth noting that the analysis considered only variables with a load of at least 0.5 components.

Generally, the main components were defined by the most central loading factors. The first factor (D1) reflects the perceived economic impact of drought, with all variables (threatening food security, unable to take preferred meals and reducing household income) describing the economic impact with positive factor loads. The first dimension (D1) was referred to as the "perceived economic impact" due to the set of variables describing the component. The economic impacts usually in the agricultural sector are due to the dependence of the surface and groundwater suppliers on the sector. Drought is associated with insect infestations, plant diseases and wind erosion, leading to crop and livestock losses and, as a result, to a reduction in household farm income. In addition, many households continue to experience food insecurity and malnutrition during drought periods. Drought also causes an increase in staple food prices, which can lead to hunger, malnutrition and poverty during periods of drought. The second component or dimension (D1) consists of four environmental variables; hence referred to as the "perceived environmental impact of drought" reflects what was perceived by respondents as the impact of drought on biodiversity and ecosystems. 


\begin{tabular}{lccc}
\hline Variable & \multicolumn{3}{c}{ Components } \\
& D1 & D2 & D3 \\
\hline Economic impact & $\mathbf{0 . 8 0 7 5}$ & 0.0288 & 0.0576 \\
Threatening food security & $\mathbf{0 . 6 5 5 7}$ & -0.0373 & 0.3552 \\
Unable to take preferred meal & $\mathbf{0 . 5 9 8 5}$ & -0.2899 & 0.2789 \\
Causes malnutrition & $\mathbf{0 . 7 7 0 8}$ & -0.0797 & 0.0324 \\
Reduction in household income & & & \\
Environmental impact & -0.2680 & $\mathbf{0 . 5 9 1 5}$ & -0.2814 \\
Migration of wildlife & -0.0173 & $\mathbf{0 . 8 1 2 4}$ & 0.0284 \\
Loss of vegetation & -0.0080 & $\mathbf{0 . 7 9 2 5}$ & -0.1505 \\
Frequent wild fires & -0.0653 & $\mathbf{0 . 8 3 2 6}$ & -0.0862 \\
Drying of water resources & & & \\
Social impact & 0.1517 & 0.0895 & $\mathbf{- 0 . 6 1 3 8}$ \\
Result in unemployment & 0.2309 & -0.0469 & $\mathbf{0 . 7 4 7 7}$ \\
Population migration & 0.1684 & -0.1445 & $\mathbf{0 . 7 7 8 7}$ \\
Reduces expenditure on social & & & \\
festivities & 0.811 & & \\
KMO measure of sampling adequacy & $1079.38 * * *$ & & \\
Bartlett's Test of Sphericity & 35.33 & 46.54 & 55.54 \\
Cumulative \% of variance & & & \\
\hline$* * *$ denotes significant at 1\% &
\end{tabular}

The impact of drought on the environment may result in damage to the quality of the air and water, forest and range fires and wildlife habitats and damage to the quality of the landscape.

Degrading the quality of the landscape, including increased soil erosion, may lead to more permanent loss of biological productivity (Wilhite and Vanyarkho, 2000). The third dimension (D3) of the perceived impact of drought has a positive impact on population migration and a reduction in expenditure on social events (e.g. naming ceremonies, festivals, marriage ceremonies, etc.) but has a negative impact on unemployment. It reflects the perceived impact of drought on people's social lives; therefore, it is referred to as the "perceived social impact of drought." The three dimensions of the PCA are the dependent variables of the SUR analysis and the results are explained in section 3.4 below. 


\subsection{Determinants of perceived impact of drought}

438 In order to guide effective and efficient policy options for climate change in general, and 439 drought in particular, it is important to understand the factors that influence farmers' perceived 440 impact of drought in three perspectives: economic, environment and social. Table 5 present the 441 coefficient estimates of the perceived economic, environmental and social impact of drought 442 from SUR model. From the SUR model, we performed correlation analysis to test the 443 hypothesis that the error components of the three perceived impact equations are not correlated 444 via the use of Breush-Pagan test. The test suggests that the null hypothesis of independence of 445 economic, environmental and social impact should be rejected at one percent level of 446 significance. Thus, it is appropriate to fit the three perceived impact equations using the SUR 447 model.

Table 5: SUR model of perceived economic, environmental and social impact of drought

\begin{tabular}{|c|c|c|c|c|c|c|}
\hline \multirow[b]{2}{*}{ Variables } & \multicolumn{2}{|c|}{ Economic } & \multicolumn{2}{|c|}{ Environmental } & \multicolumn{2}{|c|}{ Social } \\
\hline & Coeff. & Std. error & Coeff. & Std. error & Coeff. & Std. error \\
\hline Gender & $0.6287 * * *$ & 0.2143 & $0.4293 * *$ & 0.2180 & 0.0165 & 0.1959 \\
\hline Age & 0.0098 & 0.0103 & $-0.0369 * * *$ & 0.0106 & $-0.0163^{*}$ & 0.0095 \\
\hline Educational attainment & 0.0362 & 0.0321 & -0.0535 & 0.0327 & -0.0462 & 0.0294 \\
\hline Household size & $-0.0555^{* * *}$ & 0.0113 & $0.0524 * * *$ & 0.0115 & $0.0237 *$ & 0.0104 \\
\hline Farming experience & $-0.8868 * *$ & 0.3696 & $-0.9311 * *$ & 0.3760 & -0.4606 & 0.3378 \\
\hline \multicolumn{7}{|l|}{ Monthly income } \\
\hline less than 2000 & $1.8516 * *$ & 0.9555 & $-2.6126^{* *}$ & 0.9721 & $-3.0408 * *$ & 0.8733 \\
\hline $2001-5000$ & $1.7575^{*}$ & 0.9961 & $-2.1796^{* *}$ & 1.0133 & $-2.9553 * *$ & 0.9105 \\
\hline$>5000$ & 1.5387 & 1.0140 & -1.4405 & 1.0315 & $-3.1954 * *$ & 0.9268 \\
\hline Non-farm income & 0.0294 & 0.0717 & $-0.1153 *$ & 0.0783 & 0.0668 & 0.0656 \\
\hline Access to climate change inf. & $0.0862 * * *$ & 0.0088 & $0.2684 * * *$ & 0.0898 & -0.0802 & 0.0807 \\
\hline Drought frequency & $-0.9280 * * *$ & 0.0894 & $0.1780 *$ & 0.0910 & $0.2663 * * *$ & 0.0818 \\
\hline FBO membership & 0.1306 & 0.0865 & -0.0199 & 0.0879 & -0.0921 & 0.0791 \\
\hline Extension services & -0.0379 & 0.0769 & -0.1153 & 0.0783 & -0.0861 & 0.0703 \\
\hline Constant & -1.5957 & 1.2909 & 3.6499 & 1.3132 & 4.2492 & 1.1798 \\
\hline$R$-squared & 52.94 & & 50.29 & & 45.61 & \\
\hline \multicolumn{7}{|c|}{ Breush-Pagan test of independence: Chi $^{2}(3)=134.94 ; \operatorname{Pr}=0.000$} \\
\hline
\end{tabular}

450 The respondent's gender leads to a positive perception of the economic and environmental 451 impact of drought, but has no significant impact on the perception of the social impact of 
drought by the respondents. As a result, males are more in agreement with the devastating economic and environmental impact of drought. The age of respondents has a negative relationship with how the environmental and social impact of drought is perceived.

This suggests that elderly people perceived less severe environmental and social impacts of drought. This is quite surprising, as we expect older and more experienced farmers to see a serious impact on environmental and social livelihoods from drought. Mamba (2016) noted that the age of farmers determined how they perceived the impact of climate change on their livelihoods. Similarly, a respondent with many household members perceived a higher negative impact of drought on their livelihoods. This could be due to the fact that households with many mouths to feed suffer the most during drought, which will exasperate their negative perception of the economic, environmental and social impact of drought.

Another important variable that significantly influences how farmers perceive the impact of drought on their livelihoods is the number of years in farming. Experienced farmers have indigenous knowledge and are capable of perceiving climate variability and change and its consequences on the environment and agricultural household income. In addition, the lower and middle income classes perceived a greater economic impact of drought. This is far-fetched as the group of people with lower and middle incomes easily suffers when food costs are higher, resulting in food insecurity, malnutrition and poverty.

Table 5 also shows that access to information on climate change and variability has a positive impact on their perception of the economic and environmental impact of drought. Access to climate information makes farmers aware of the impact on their livelihoods of climate change and employs measures to mitigate the negative results. Therefore, the more farmers access drought-related information, the more they perceive and plan. This suggests the need to make climate information easily accessible to farmers in order to improve planning for 
drought adaptation and to mitigate adverse effects on their lives and the environment. Other

477 studies (Ehiakpor et al., 2016; Ojo and Baiyegunhi, 2020; Thinda et al., 2020) have shown, similar to this study, that access to information on climate change gives farmers a better understanding of the climate impact, leading to better planning and implementation of measures against the negative effects of climate change, particularly drought. Likewise, the frequency of droughts experienced by farmers leads to a greater perception of the effect of droughts on people's economic and social lives as well as on the environment. This is not surprising because not only have those farmers heard of drought, but had experienced drying up of rivers, heat waves, lower rainfall and longer dry seasons. Smallholder farmers who experience drought usually lose their crops and livestock and face lower levels of income, food insecurity, malnutrition and unemployment as a result. Drought causes a depletion in the saving account of farmers and a limited growth potential in the next season's calving rate, according to the Bureau for Food and Agricultural Policy (2015), which consequently have long-term adverse effects on households' economic and social resilience.

\subsection{Determinants of intensity of drought-risk management strategies}

Determinants of intensity of drought-risk management practices adopted by agricultural households in the study area are reported in Table 6. Two count data models were estimated: Poisson regression and Negative binomial regression models. Model diagnostic tests were performed to determine whether Poisson or negative binomials fit the data properly. The $L R$ $C h i^{2}$ value for Poisson is relatively large (60.56) compared to the negative binomial (56.50), suggesting that the Poisson regression model fits the data appropriately. The lnapha parameter for the negative binomial regression model is small and not significant even at the $10 \%$ level of significance, suggesting that the null hypothesis of equidispersion for the Poisson regression model cannot be rejected. In addition, the Akaike Information Criterion (AIC) and Bayesian Information Criterion (BIC) estimates are important diagnostic tests to identify a better model 
for the regression analysis. The AIC and BIC tests revealed that the Poisson model had lower values than the negative binomial model; therefore, the Poisson model was a better option. Thus, all diagnostic tests indicate that the Poisson model fits the data significantly well and should therefore be the focus model.

From Table 6, two variables of household demographic characteristics: age and household size influence the intensity of drought-risk management practices. The age of the respondent responds negatively to the number of drought-risk management practices adopted, suggesting that elderly is less responsive to adopting a number of strategies to combat the negative impact of drought compared to young and energetic respondents. This could be attributed to the fact that the younger generation is more innovative, less risky, always looking for information and ready to improve agricultural productivity. Older farmers may not be aware of modern agricultural innovations and strategies to minimize the risks and adverse effects of drought. This is consistent with the study of Ali and Erenstein (2017). Household size is negatively correlated with the number of drought-risk management practices adopted by farmers. This could be because drought-risk measures such as crop insurance, maintaining flexibility (e.g., planting drought-tolerance crop varieties) are quite expensive and households with large financial burdens due to many dependents may not afford to purchase these coping strategies. Although large household sizes are mostly considered to be farm and non-farm labour supplies, as many studies have noted (Abid et al., 2015; Zereyesus et al., 2017), this may not be the case for households with members who are young (usually children) because such households will need high costs to meet their family needs. These households are usually unable to take ex ante measures (e.g., purchase of crop insurance, drought-tolerance varieties) and can only adopt ex post strategies (e.g., sale of assets, decrease in food consumption and borrowing from neighbours) to cope with the drought situation. However, farmers with long-standing 

the risk of drought.

Table 6. Results on the determinants of intensity of drought-risk management strategies

\begin{tabular}{lcccc}
\hline & \multicolumn{2}{c}{ Poisson regression } & \multicolumn{2}{c}{ Negative binomial } \\
Explanatory variables & Coeff. & Std. & Coeff. & Std. \\
\hline Gender & -0.0175 & 0.0563 & -0.0175 & 0.0563 \\
Age & $-0.0045^{* *}$ & 0.0010 & $-0.0045^{* *}$ & 0.0019 \\
Education & 0.0011 & 0.0083 & 0.0011 & 0.0082 \\
Experience & 0.1331 & 0.0938 & 0.1331 & 0.0938 \\
Household size & $-0.0271^{*}$ & 0.0146 & $-0.0271^{* *}$ & 0.0146 \\
Non-farm work & $-0.1446^{* * *}$ & 0.0482 & $-0.1446^{* * *}$ & 0.0482 \\
Membership of farmer associations & -0.0372 & 0.0242 & -0.0371 & 0.0242 \\
Access to extension services & $0.0495^{* *}$ & 0.0249 & $0.0495^{* *}$ & 0.0248 \\
Access to climate change information & 0.0093 & 0.0235 & 0.0093 & 0.0235 \\
Drought frequency & -0.0068 & 0.0242 & -0.0068 & 0.0242 \\
Perceived economic impact (D1) & $-0.0804^{* * *}$ & 0.0307 & $-0.0804 * *$ & 0.0308 \\
Perceived environmental impact (2) & -0.0223 & 0.0311 & -0.0223 & 0.0313 \\
Perceived social impact (D3) & $0.1114^{* * *}$ & 0.0331 & $0.1113 * *$ & 0.0331 \\
Constant & 1.8162 & 0.1892 & 1.8161 & 0.1892 \\
lnalpha & & & 16.2696 & 460.9285 \\
LR test of alpha & & & 0.000 & 0.5000 \\
Pseudo $R$ & & & & \\
LR Chi-square & & & & \\
Probability > Chi & 60.56 & & 1371.43 & \\
AIC & & & 1430.69 & \\
BIC & 1369.43 & & 300 & \\
Number of observations & 1424.98 & & & \\
***,**, and * denote significant at 1\%, 5\% and 10\%, respectively. &
\end{tabular}
$* * *, * *$, and $*$ denote significant at $1 \%, 5 \%$ and $10 \%$, respectively. on the number of drought-risk management strategies farmers practiced. Thus, farmers who have other sources of income are less likely to adopt more of the listed drought management practices compared with farmers who depend on agricultural activities as their sole source of livelihood. Participation in non-farm work offers households alternative sources of income that allow them to avoid certain measures such as selling assets (e.g. farmland, livestock, etc.), reducing food consumption, among others. During drought, some household members

536 (especially the husband) migrate to other areas to engage in non-agricultural economic activities to meet the family's needs. This reduces the number of 'hard' drought coping strategies employed. Access to extension also plays a vital role in the intensity of drought-risk 
management strategies, as indicated by a positive and significant coefficient. Extension services provide information through which farmers know what's going on in their environment. Providing farmers with information not only on farm management practices, but also on how to prepare themselves to face the risk of extreme weather conditions, such as drought, helps farmers psychologically cope with drought stress. Asfaw et al. (2018) noted that there is a positive and significant link between climate change coping strategies and farmers' access to extension services.

In addition, farmers who perceived severe economic and social impacts of drought tend to use more of the drought-risk management strategies to mitigate the negative outcomes. The direct economic impact of drought in the agricultural sector is usually the loss of crops and livestock, which causes negative supply shocks and destabilizes the structure of the agricultural market. Farmers who perceived severe outcome of such disruption used strategies such as rainwater harvesting as a source of drinking water for themselves and animals, as well as irrigating their crops. Some other farmers store food crops such as maize, rice, etc. as reserves and residues for their animals. In addition, farmers who perceived drought to have a very severe impact on their crops may purchase crop insurance, which will be compensated by insurance companies for a proportion of their crop losses. They may also register and receive disaster assistance from NGOs and the government. Drought may, however, create winners. This is because farmers who have perceived the higher impact of drought on food prices may take advantage of this by hauling their crop output to benefit from favourable prices. Consequently, the negative economic impact of drought is not entirely borne by farmers, part of which is passed on to consumers (Ching et al. 2011). 


\section{Conclusions and policy recommendations}

564 Irregular and unforeseen variations in climate present difficult situations for the world, 565 particularly those that depend on agricultural activities as their primary source of livelihood.

566 Extreme weather conditions such as drought are one of the major contributors to food 567 insecurity, malnutrition and poverty. The extent to which farmers have perceived the impact of 568 drought on socio-economic life and the environment, as well as their management strategies, 569 is crucial to policy implications. This study made small but significant contributions to the 570 empirical literature on climate change in three ways: (1) analysed how farmers see the impact 571 of drought on their livelihoods through PCA; (2) identified the determinants of perceived impact of drought using SUR; and (3) examined factors that influence the intensity of droughtrisk management strategies used by farmers in the Thaba Nchu mun using count data modelling.

PCA results show that farmers understand how climate change, particularly drought, affects their lives and the environment, and that, on average, farmers feel that the impact of drought is serious. Gender, age, household size and farming experience are demographic factors that tend to influence their perception of the impact of drought. Access to information on climate change was also a significant factor in how farmers perceived the impact of drought. Knowledge is a significant precursor for people to form their perception, which is intended to help them adapt appropriately to situations. In the event of drought, farmers with prior information may be less vulnerable as they may have prepared themselves in advance. It is therefore important to strengthen improved early warning systems in local communities in order to reduce vulnerability. The dissemination of such climate information to provide prospects with lead times of two to six months prior to the start of the event will help farmers plan their adaptation and coping strategies. 
The results further indicated that obtaining assistance from NGOs and communities and selling or mortgaging their farmland are common drought-risk management strategies used by farmers to cope with the negative outcome of the drought. Factors that have a significant effect on intensity of drought-risk management strategies include age, household size, non-farm work and extension services. The study therefore recommends that demand-driven extension services that address the needs of people at a particular point in time is critical to the lives of farmers. Climate risk management can be integrated into the provision of extension services, particularly in drought-prone areas such as the province of Free State. In this case, farmers are not only trained in agricultural technology, but also in the management of drought-risk. This makes farmers less vulnerable to climate shocks and serves as a strategy to combat food insecurity and long-term poverty. Encouraging farmers to engage in non-agricultural economic activities is also critical, as this can serve as insurance against events such as drought.

\section{Declarations}

\section{Availability of data and materials}

The datasets used to analyse this study are available from the corresponding author on reasonable request.

\section{Competing interests}

The authors declare that there exists no competing interest.

\section{Funding}

The study did not receive direct funding for publication.

\section{Authors' Contribution}

All authors contributed to the different stages of the study. GDA conceptualized the idea, was involved in the analysis of the data, and wrote the draft manuscript. AOO supervised the study 
and provided comments on the manuscript. TOO was actively involved in the data analysis and interpretation. CCO collected the data. All authors read and approved the final manuscript.

\section{Acknowledgement}

The paper is based on research that was conducted as part of a research project, "farmers' coping and adaptation strategies to drought and other water related risks in a changing climate (TTK160610170148)", which was funded by the National Research Foundation (NRF) through the Thuthuka funding instrument (NRF rating track) grant. Financial and other assistance by the NRF are gratefully acknowledged. Financial assistance by the University of the Free State through the Central Research Fund (CRF) of the Faculty of Natural and Agricultural Sciences is also gratefully acknowledged.

\section{References}

Abid, M., Scheffran, J., Schneider, U. A., \& Ashfaq, M. (2015). Farmers' perceptions of and adaptation strategies to climate change and their determinants: the case of Punjab province, Pakistan. Earth System Dynamics, 6(1), 225-243.

Alam, G. M., Alam, K., \& Mushtaq, S. (2017). Climate change perceptions and local adaptation strategies of hazard-prone rural households in Bangladesh. Climate Risk Management, $17,52-63$.

Ali, A., \& Erenstein, O. (2017). Assessing farmer use of climate change adaptation practices and impacts on food security and poverty in Pakistan. Climate Risk Management, 16, 183-194.

Asante, B. O., Villano, R. A., Patrick, I. W., \& Battese, G. E. (2018). Determinants of farm diversification in integrated crop-livestock farming systems in Ghana. Renewable Agriculture and Food Systems, 33(2), 131. 
640

641

642

643

644

645

646

647

648

649

650

651

652

653

654

655

656

657

658

659

660

661

662

663

664

Asfaw, S., Pallante, G., \& Palma, A. (2018). Diversification strategies and adaptation deficit: Evidence from rural communities in Niger. World Development, 101, 219-234.

Bawakyillenuo, S., Yaro, J. A., \& Teye, J. (2016). Exploring the autonomous adaptation strategies to climate change and climate variability in selected villages in the rural northern savannah zone of Ghana. Local Environment, 21(3), 361-382.

Bellon, M. R., Kotu, B. H., Azzarri, C., \& Caracciolo, F. (2020). To diversify or not to diversify, that is the question. Pursuing agricultural development for smallholder farmers in marginal areas of Ghana. World Development, 125, 104682.

Bureau for Food and Agricultural Policy. 2015. Policy brief on the 2015/2016 drought. Integrated Value Information System: 4-17.

Botai, C. M., Botai, J. O., Dlamini, L. C., Zwane, N. S., \& Phaduli, E. (2016). Characteristics of droughts in South Africa: a case study of free state and north west provinces. Water, $8(10), 439$.

Bryan, E., Deressa, T. T., Gbetibouo, G. A., \& Ringler, C. (2009). Adaptation to climate change in Ethiopia and South Africa: options and constraints. Environmental science \& policy, $12(4), 413-426$.

Cameron, \& Trivedi, P. K. (1990). Regression-based tests for overdispersion in the Poisson model. Journal of Econometrics, 46(3), 347-364.

Cameron, A., \& Trivedi, P. (2010). September 2010. Microeconometrics Using Stata, Revised Edition. StataCorp LP.

Ching, L., Edwards, S., \& El-Hage, S. N. (2011). Climate change and food systems resilience in sub-Saharan Africa. Food and Agriculture Organization of the United Nations (FAO).

Dai, A. (2013). Increasing drought under global warming in observations and models. Nature climate change, 3(1), 52-58. 
Ehiakpor, D. S., Danso-Abbeam, G., \& Baah, J. E. (2016). Cocoa farmers' perception on climate variability and its effects on adaptation strategies in th Suaman district of western region, Ghana. Cogent Food and Agriculture, 2(1210557).

Field, A. (2009) Discovering Statistics using SPSS for Windows, 3rd edn. London, UK: Sage Publications

Greene, W. H. (2008). Econometric analysis, 6th edn. Upper Saddle River NJ: Pearson, Upper Saddle River NJ.

Hair Jr, J. F., Sarstedt, M., Hopkins, L., \& Kuppelwieser, V. G. (2014). Partial least squares structural equation modeling (PLS-SEM): An emerging tool in business research. European business review.

Hassan, R. M., \& Nhemachena, C. (2008). Determinants of African farmers' strategies for adapting to climate change: Multinomial choice analysis. African Journal of Agricultural and Resource Economics, 2(311-2016-5521), 83-104.

Hansen, J.W., Dilley, M., Goddard, L., Ebrahimian, E., Ericksen, P., 2004. Climate

Variability and the Millennium Development Goal Hunger Target. IRI Technical Report No. 04-04.

Hellmuth, M., Osgood, D., Hess, U., Moorhead, A., \& Bhojwani, H. (2009). Climate and society, No. 2. IRI, Columbia University, New York, USA.

IPCC (2014). AR5 climate change 2014: impacts, adaptation, and vulnerability. Intergovernmental Panel on Climate Change. Available:

https://www.ipcc.ch/report/ar5/wg2/. Accessed 11/20/2019

Israel, M. A., Amikuzuno, J., \& Danso-Abbeam, G. (2020). Assessing farmers' contribution to greenhouse gas emission and the impact of adopting climate-smart agriculture on mitigation. Ecological Processes, 9(1), 1-10. 
690

691

692

693

694

695

696

697

698

699

700

701

702

703

704

705

706

707

708

709

710

711

712

713

714

Keesstra, S. (2007). Impact of natural reforestation on floodplain sedimentation in the Dragonja basin, SW Slovenia. Earth Surface Processes and Landforms: The Journal of the British Geomorphological Research Group, 32(1), 49-65.

Kogo, B. K., Kumar, L., \& Koech, R. (2020). Climate change and variability in Kenya: a review of impacts on agriculture and food security. Environment, Development and Sustainability, 1-21.

Linke, A. M., Witmer, F. D., \& O’Loughlin, J. (2020). Do people accurately report droughts? Comparison of instrument-measured and national survey data in Kenya. Climatic Change, 162(3), 1143-1160.

Maddala, G., \& Flores-Lagunes, A. (2001). Qualitative response models. A companion to theoretical econometrics, 366.

Mahama, A., Awuni, J. A., Mabe, F. N., \& Azumah, S. B. (2020). Modelling adoption intensity of improved soybean production technologies in Ghana-a Generalized Poisson approach. Heliyon, 6(3), e03543.

Mangaung Metropolitan Municipality Draft Integrated Development Plan. 2017. Impact on farmers and the agricultural sector. Available online:

http://www.thabomofutsanyana.gov.za/downloads/Final\%20IDP\%202014-15.pdf.

Mamba, S. F. (2016). Factors influencing perception of climate variability and change among smallholder farmers in Swaziland. Indian Journal of Nutrition, 3(2), 138-142.

Maponya, P., \& Mpandeli, S. (2013). Perception of farmers on climate change and adaptation in Limpopo Province of South Africa. Journal of Human Ecology, 42(3), 283-288.

Martey, E., \& Kuwornu, J. K. (2021). Perceptions of Climate Variability and Soil Fertility Management Choices Among Smallholder Farmers in Northern Ghana. Ecological Economics, 180, 106870. 
Moeletsi, M. E., \& Walker, S. (2012). Assessment of agricultural drought using a simple water balance model in the Free State Province of South Africa. Theoretical and applied climatology, 108(3-4), 425-450.

Mohmmed, A., Zhang, K., Kabenge, M., Keesstra, S., Cerdà, A., Reuben, M., . . Ali, A. A. (2018). Analysis of drought and vulnerability in the North Darfur region of Sudan. Land Degradation \& Development, 29(12), 4424-4438.

Msangi, J. (2004). Drought hazard and desertification management in the drylands of Southern Africa. Environmental monitoring and assessment, 99(1-3), 75-87.

Nanganga, J., \& Safalaoh, A. C. (2020). Climate Change and Weather Variability Effects on Cattle Production: Perception of Cattle Keepers in Chikwawa, Malawi Climate Impacts on Agricultural and Natural Resource Sustainability in Africa (pp. 213-225): Springer.

Niles, M. T., Lubell, M., \& Haden, V. R. (2013). Perceptions and responses to climate policy risks among California farmers. Global Environmental Change, 23(6), 1752-1760.

Nkegbe, P. K., \& Shankar, B. (2014). Adoption intensity of soil and water conservation practices by smallholders: evidence from Northern Ghana. Bio-based and Applied Economics Journal, 3(1050-2016-85757), 159-174.

Ojo, T., \& Baiyegunhi, L. (2020). Determinants of climate change adaptation strategies and its impact on the net farm income of rice farmers in south-west Nigeria. Land Use Policy, 95, 103946.

Owens, T., Hoddinott, J., \& Kinsey, B. (2003). Ex-ante actions and ex-post public responses to drought shocks: Evidence and simulations from Zimbabwe. World Development, 31(7), 1239-1255.

Panthi, J., Aryal, S., Dahal, P., Bhandari, P., Krakauer, N. Y., \& Pandey, V. P. (2016). Livelihood vulnerability approach to assessing climate change impacts on mixed agro- 
livestock smallholders around the Gandaki River Basin in Nepal. Regional Environmental Change, 16(4), 1121-1132.

Shiferaw, B., Tesfaye, K., Kassie, M., Abate, T., Prasanna, B., \& Menkir, A. (2014). Managing vulnerability to drought and enhancing livelihood resilience in sub-Saharan Africa: Technological, institutional and policy options. Weather and Climate Extremes, 3, 6779.

Shoroma, L.B. 2014. Mitigating the effects of recurrent drought: The case of Setlagole community, Ratlou Municipality (North West Province).Master's mini-dissertation, NorthWest University.

South African Weather Service (SAWS). Meteorological Services under the South African Government. 2015. http://www.weathersa.co.za/web/index.php.

Statistics South Africa (Stats SA). 2011. Available online: http://www.statssa.gov.za/?page_id=993\&id=mangaung-municipality.

Tavakol, M., \& Dennick, R. (2011). Making sense of Cronbach's alpha. International journal of medical education, 2, 53.

Tesso, G., Emana, B., \& Ketema, M. (2012). Analysis of vulnerability and resilience to climate change induced shocks in North Shewa, Ethiopia. Agricultural Sciences, 3(06), 871.

Thilakarathne, M., \& Sridhar, V. (2017). Characterization of future drought conditions in the Lower Mekong River Basin. Weather and Climate Extremes, 17, 47-58.

Thinda, K., Ogundeji, A., Belle, J., \& Ojo, T. (2020). Understanding the adoption of climate change adaptation strategies among smallholder farmers: Evidence from land reform beneficiaries in South Africa. Land Use Policy, 99, 104858.

Thomas, D. S., Twyman, C., Osbahr, H., \& Hewitson, B. (2011). Adaptation to climate change and variability: Farmer responses to intra-seasonal precipitation trends in South Africa African Climate and Climate Change (pp. 155-178): Springer. 
77

Wale, Z. E., Unity, C., \& Nolwazi, H. (2021). Towards identifying enablers and inhibitors to on-farm entrepreneurship: evidence from smallholders in KwaZulu-Natal, South Africa. Heliyon, 7(1), e05660.

Wilhite, D. A., \& Vanyarkho, O. V. (2000). Drought: Pervasive impacts of a creeping phenomenon.

Williams, P. A., Crespo, O., \& Abu, M. (2019). Adapting to changing climate through improving adaptive capacity at the local level-The case of smallholder horticultural producers in Ghana. Climate Risk Management, 23, 124-135.

Zereyesus, Y. A., Embaye, W. T., Tsiboe, F., \& Amanor-Boadu, V. (2017). Implications of non-farm work to vulnerability to food poverty-recent evidence from Northern Ghana. World Development, 91, 113-124. 


\section{Figures}

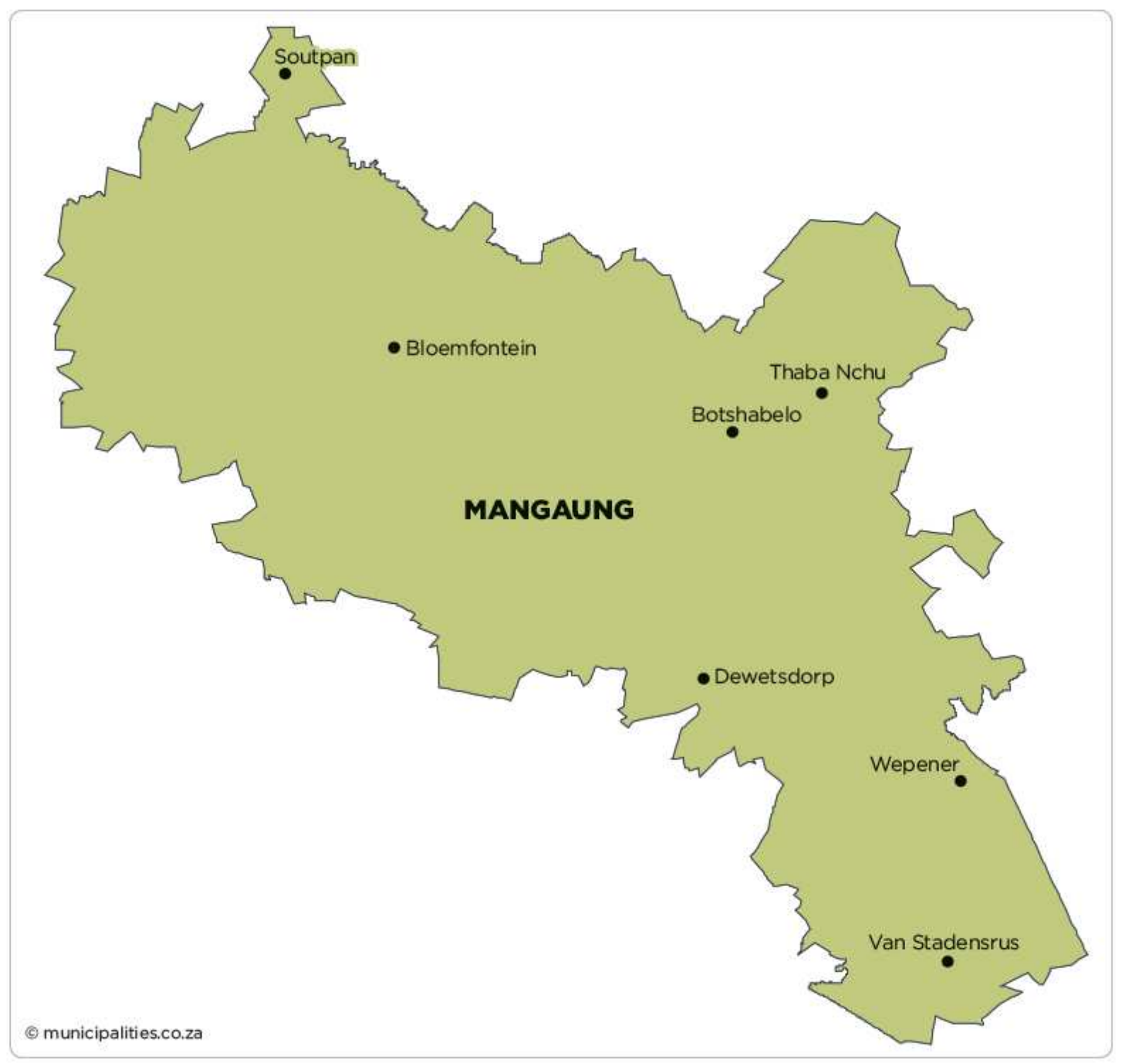

\section{Figure 1}

A map of Mangaung district showing Thaba Nchu Municipality, Free State Province, South Africa. Note: The designations employed and the presentation of the material on this map do not imply the expression of any opinion whatsoever on the part of Research Square concerning the legal status of any country, territory, city or area or of its authorities, or concerning the delimitation of its frontiers or boundaries. This map has been provided by the authors. 